\title{
Home Production and Social Security Reform*
}

\author{
Michael Dotsey Wenli Li Fang Yang ${ }^{\dagger}$
}

February 2012

\begin{abstract}
This paper incorporates home production into a dynamic general equilibrium model of overlapping generations with endogenous retirement to study Social Security reforms. As such, the model differentiates both consumption goods and labor effort according to their respective roles in home production and market activities. Using a calibrated model, we find that eliminating the current pay-asyou-go Social Security system has important implications for both labor supply and consumption decisions and that these decisions are influenced by the presence of a home production technology. Specifically, without Social Security benefits households work much more in the market, especially in old age, while young households also engage more in home production. For consumption, households increase their consumption of housing services - an input for home production - to a greater extent than for other market-produced goods. Comparing our benchmark economy to one with differentiated goods but no home production, we find that eliminating Social Security benefits generates larger welfare gains in the presence of home production. This result is due to the self insurance aspects generated by the presence of home production. Comparing our economy to a one-good economy without home production, we show that the welfare gains of eliminating Social Security are magnified even further. These policy analyses suggest the importance of modeling home production and distinguishing between both time use and consumption goods depending on whether they are involved in market or home production.
\end{abstract}

${ }^{*}$ The views expressed are those of the authors and do not necessarily reflect those of the Federal Reserve Bank of Philadelphia or the Federal Reserve System. We thank seminar participants at the 2011 Midwest Macroeconomic Meetings, the Federal Reserve Bank of Atlanta and Emory University for their comments. Yang acknowledges support from Individual Development Awards Program at United University Professions. This paper is available free of charge at www.philadelphiafed.org/research-and-

${ }^{\dagger}$ Michael Dotsey and Wenli Li: Research Department, Federal Reserve Bank of Philadelphia, Ten Independence Mall, Philadelphia, PA 19106 (email: michael.dotsey@phil.frb.org; wenli.li@phil.frb.org). Fang Yang: Department of Economics, State University of New York at Albany, Albany, NY 12222 (email: fyang@albany.edu). 
JEL Classifications: E21, E62, H55

Keywords: Home Production, Housing, Social Security Reform, Labor Supply 


\section{Introduction}

The significant challenges facing the unfunded U.S. Social Security have stimulated a large economic literature analyzing the implications of Social Security reforms. The models used for this purpose are quite diverse and include features such as altruism, liquidity constraints, longevity and individual income risks, the separation of labor participation and hours worked, endogenous benefit claims, and housing. ${ }^{1}$ This paper makes an important contribution to this literature by incorporating home production into a general equilibrium model of overlapping generations with endogenous labor supply. We find that a carefully calibrated model with home production better matches life cycle consumption and labor profiles and is, therefore, a more reliable setting for analyzing the effects of various reforms to Social Security. We show that including home production produces larger long-run welfare gains in response to an elimination of Social Security benefits and the associated distortionary taxes needed to fully fund the program than those in an economy without home production. We also demonstrate the importance of disaggregating consumption goods based on whether they can be produced at home, because home production introduces insurance possibilities that are not present when only market-produced goods are available.

More specifically, a key way that models with home production differ from more standard models is that home production allows households to substitute between additional margins, both in labor supply (market hours versus home hours) and in consumption (market-produced goods versus home-produced goods). Recent research has shown that these margins are important in households' labor supply and consumption decisions. For example, Rogerson (2009) shows that introducing home production in a standard labor supply model implies that differences in tax and transfer systems can explain one quarter of the differences in hours of work across countries, and Rogerson and Wallenius (2009) demonstrate that home production alone is qualitatively capable of generating retirement. Additionally, Aguiar and Hurst (2009) suggest that home production plays an important role in understanding the behavior of consumption at retirement, while Dotsey, Li, and Yang (2010) show that home production indeed is crucial in matching households' consumption of different goods and labor supply over the life cycle. ${ }^{2}$

As is standard in the literature, we include residential capital stock (housing) in

\footnotetext{
${ }^{1}$ See, among many others, Fuster (1999), Fuster, Imrohoroglu and Imrohoroglu (2003, 2007), Nishiyama and Smetters (2007), Imrohoroglu and Kitao (2009, 2012), and Chen (2010).

${ }^{2}$ The incorporation of home production in otherwise standard macro models has also proven useful in understanding a variety of macroeconomic issues, including domestic and international business cycles, fiscal policies, and asset equilibrium puzzles (see, among many others, Baxter and Jermann 1997, Benhabib, et al. 1991, Gomme, et al. 2001, Greenwood and Hercowitz 1991, Greenwood, et al. 1995, McGratten, et al. 1997, and Chang and Hornstein 2008).
} 
home production. We, however, differentiate home input, an intermediate market good, from residential capital stock and model it as an additional input to home production. We allow households' preference over different goods and leisure as well as their home production technology to take flexible functional forms that exhibit constant elasticity of substitution. Additionally, we endogenize households' decisions to claim Social Security benefits along the lines of Imrohoroglu and Kitao (2012). Finally, our model captures many realistic features of the Social Security system, such as the link between households' Social Security benefits and their past earnings and age when benefits are initially claimed.

We calibrate the preference parameters and home production technology to match various aggregate moments of the micro data on consumption and time use. Our model with home production generates household life cycle consumption and labor supply profiles that are consistent with those estimated from the micro data. ${ }^{3}$ With these parameterizations, we conduct a policy experiment in which we eliminate Social Security benefits completely and compute changes in steady-state levels of labor hours, consumption, and welfare. We show that both labor hours and total consumption respond strongly to the elimination of Social Security. In particular, market hours move up sharply (6.2 percent), while leisure comes down significantly ( -1.5 percent). Home hours change little (0.4 percent). In terms of consumption, housing experiences the largest increase (17.1 percent), followed by the market good (3.4 percent) and then the home input (0.6 percent).

Two key channels drive the results above. First, as is standard in the literature, elimination of Social Security increases precautionary savings and saving for retirement, which raises the steady-state capital stock. This leads to a reduction in the steady-state interest rate and in the cost of housing services. As a result, consumption of housing services increases, which in turn drives up hours in home production. ${ }^{4}$ Second, the elimination of the payroll tax induces people to substitute away from home production and into market production. This substitution effect, however, is offset by the positive wealth effect coming from higher wages and the fact that the increase in housing services makes home production more productive after the reform.

To analyze the importance that home production makes in assessing the welfare consequences of removing Social Security, we recalibrate our benchmark economy without home production and keep the three consumption goods - housing, home inputs, and market goods - separate. We show that the new economy generates consumption and

\footnotetext{
${ }^{3}$ A detailed discussion of how home production influences the ability of a life-cycle model to match life cycle profiles of time use and various types of consumption goods is contained in our 2011 paper.

${ }^{4}$ Chen (2010) demostrates a large increase of housing in an enviroment without time allocation.
} 
labor profiles that are somewhat worse than the benchmark. After eliminating Social Security, aggregate capital goes up more than in the benchmark economy as households desire more precautionary savings. Labor supply in this model increases more than that in the benchmark model, where the increase of labor supply is constrained by the increase in home hours caused partly by the upward pressure from higher housing consumption. Further, housing, which is no longer related to home hours, increases even more than in the benchmark model. The steady-state welfare gains are 16.1 percent, which is 3 percentage points smaller than the welfare gains of eliminating Social Security in the benchmark. The reason is that the presence of home production provides a form of insurance to the household. In response to bad labor productivity shocks, the household can insure itself by substituting out of market activity and into home production. This channel helps complete the market and is particularly important for older households with low market labor efficiency.

Finally, we write down a one-good economy to facilitate the comparison of our benchmark to the existing Social Security literature, which not only does not have home production but also typically abstracts from consumption of different categories. As in our benchmark, we calibrate the economy to match a set of moments. We show that this one-good economy does not match consumption data profiles very well. Furthermore, the long-run welfare gains of eliminating Social Security benefits drop to a little over 10 percentage points, close to 9 percentage points lower than that in the benchmark case, and 6 percentage points lower than that in the economy without home production but with differentiated consumption goods. The intuition behind the welfare difference between the one-good economy and the economy with differentiated goods is that without the additional margins of adjusting consumption (or adjusting the consumption of different categories of goods depending on their relative prices), households in the one-good economy need to save more for precautionary reasons and for old age. Social Security provisions, which help households make up shortfalls in savings when old, are thus more valued. In summary, our analysis suggests that it is important not only to incorporate home production but also to differentiate consumption in order to assess the impact of changes to the Social Security system.

The rest of the paper is organized as follows. In section 2, we describe the model economy and in section 3, we present the model calibration. In section 4 , we conduct the experiment of eliminating Social Security and in section 5 , we recalibrate the model without home production and conduct the same policy experiment. Section 6 examines the model with only one good. Section 7 concludes. 


\section{The Model Economy}

Our model economy follows Dotsey, Li, and Yang (2010) with two exceptions. Social Security benefits now depend on households' average lifetime earnings and households choose when to claim benefits, as in Imrohoroglu and Kitao (2012). Adding this important degree of realism to the model requires an additional state variable; so for computational reasons we eliminate owner-occupied housing and instead treat all housing in the economy as rental. As is shown in Chen (2010), this simplification is not likely to noticeably affect our results.

\subsection{Demographics}

The economy is populated by overlapping generations of households of age $t=1,2, . ., T$, where $T$ is the maximum possible age. The life span is uncertain and households of age $t$ face an exogenous probability of survival, $\lambda_{t}$. Since the demographic patterns are stable, agents at age $t$ constitute a constant fraction of the population at any point in time. Annuity markets are assumed to be absent and accidental bequests are distributed to all households in the economy.

\subsection{Preferences and Home Production}

Households value consumption of a composite good $c$ that consists of a market-produced nondurable good, $c_{m}$, and a home-produced good, $c_{h}$, and leisure, $l$. Preferences are assumed to be time separable, with a constant discount factor $\beta$.

Production of the home good requires a home input, housing, and labor. In particular,

$$
c_{h}=f\left(d, s, n_{h}\right)=\left\{\omega_{2}\left[\omega_{1} d^{1-\frac{1}{\zeta_{1}}}+\left(1-\omega_{1}\right) s^{1-\frac{1}{\zeta_{1}}}\right]^{\frac{1-\frac{1}{\zeta_{2}}}{1-\frac{1}{\zeta_{1}}}}+\left(1-\omega_{2}\right)\left(n_{h}\right)^{1-\frac{1}{\zeta_{2}}}\right\}^{\frac{1}{1-\frac{1}{\zeta_{2}}}}
$$

where $d$ denotes the home input, $s$ denotes the rental stock, and $n_{h}$ the labor input in home production. ${ }^{5}$ We assume that renting is the only way of consuming housing services in this economy. The parameter $\omega_{1}$ controls the weights associated with home input and housing, and the parameter $\omega_{2}$ specifies the weight associated with the resulting composite good and hours used in home production. $\zeta_{1}$ governs the intra-class substitutability between the home input and housing, and $\zeta_{2}$ governs the inter-class

\footnotetext{
${ }^{5}$ For simplicity, we have combined both nondurable expenditures such as raw food with consumer durables such as appliances into a composite durable good used in home production. We call this composite good home input. An interesting extension would be to treat these separately, especially for modelling the cyclicality of consumption.
} 
elasticity of substitution between the composite home input and hours used in home production. ${ }^{6}$

The period utility function is given by

$$
U(c, l)=\frac{\left[\omega_{4} c^{1-\frac{1}{\zeta_{4}}}+\left(1-\omega_{4}\right) l^{1-\frac{1}{\zeta_{4}}}\right]^{\frac{1-\gamma}{\zeta_{4}}}-1}{1-\gamma},
$$

where

$$
c=\left[\omega_{3} c_{m}^{1-\frac{1}{\varsigma_{3}}}+\left(1-\omega_{3}\right) c_{h}^{1-\frac{1}{\varsigma_{3}}}\right]^{\frac{1}{1-\frac{1}{\varsigma_{3}}}}
$$

The term $\omega_{4}$ represents the relative weight of the composite consumption good in utility, $\zeta_{4}$ represents the degree of substitution between the composite consumption good and leisure, $\gamma$ is the relative risk aversion parameter, $\omega_{3}$ denotes the relative weight of the market good in the composite consumption good, and $\zeta_{3}$ measures the degree of substitution between the market good and the home good.

Two features of our model are unique to the literature on Social Security and we seek to better understand the importance of these features for Social Security reform. The first and the most important is the introduction of home production, which allows households to substitute between market and nonmarket activities. The second is the modeling of different consumption goods, including housing, and allowing them to interact with nonmarket activity.

\subsection{Labor Productivity}

Labor productivity consists of two components. The first is deterministic and age dependent with all consumers of the same birth cohort facing the same exogenous profile, $e_{t}$. The second is stochastic with each worker, $i$, at age, $t$, receiving a stochastic productivity shock $\varepsilon_{t}^{i}$, which follows a Markov process

$$
\ln \varepsilon_{t}^{i}=\rho_{\varepsilon} \ln \varepsilon_{t-1}^{i}+v_{t}^{i}, v_{t}^{i} \sim N\left(0, \sigma_{\varepsilon}^{2}\right) .
$$

The Markov process is the same for all households and there is no uncertainty over the aggregate labor endowment. The total productivity of a worker at age $t$ is then given by the product of the worker's age- $t$ productivity shock and age- $t$ deterministic efficiency

\footnotetext{
${ }^{6}$ Following Sato (1967), we justify our aggregation by the fact that intra-class elasticity between home input and housing is potentially higher than the inter-class elasticity between home input and home hours or housing and home hours because home input and housing are more similar in techno-economic characteristics.
} 
index: $e_{t} \varepsilon_{t}^{i}$. Thus, this part of our model follows the vast literature that assumes this parsimonious yet empirically plausible income process.

\subsection{Borrowing Constraints}

We impose an exogenous borrowing constraint on the economy. In particular, at any given period the household's financial asset denoted by $a^{\prime}$ must satisfy

$$
a^{\prime} \geq-e^{\prime} \underline{\varepsilon}^{\prime} w
$$

where $\underline{\varepsilon}^{\prime}$ is the next period's lowest possible realization of a labor efficiency shock and $w$ denotes the economy-wide wage per efficiency unit of labor for the next period. In other words, we require that a household can only borrow up to an amount that is equal to its lowest possible labor income next period, assuming that it spends all its time working for the market.

\subsection{Market Production}

There is only one type of market good produced according to the aggregate market production function

$$
F^{m}(K, L)=K^{\alpha} L^{1-\alpha}
$$

where $K$ is the aggregate market capital stock and $L$ is the aggregate market labor input. The final good can be directly consumed, invested in physical capital, or housing, or used as an intermediate input in home production. Physical capital and housing depreciate at rates $\delta^{k}$, and $\delta^{s}$, respectively. ${ }^{7}$

\subsection{Financial Institutions}

Following Gervais (2002), we assume there exists a two-period-lived financial institution. At the end of the first period, the intermediary accepts deposits and buys residential capital. In the second period, it repays deposits with interest at rate $r$. Residential capital is then rented to agents at a price $\eta$ per unit. At the end of the second period, the financial institution sells the nondepreciated residential stock to a new agency. The

\footnotetext{
${ }^{7}$ We assume that the home input depreciates completely given that household appliances and equipment account for less than 10 percent of total home input.
} 
no-arbitrage condition implies that the rental rate on housing is given by

$$
\eta=r+\delta^{s}
$$

\subsection{Social Security}

The government operates a pay-as-you-go Social Security system similar to the current U.S. system. Specifically, the government taxes labor earnings below the Social Security cap $y_{\max }$, at a constant rate, $\tau$. Retired households receive Social Security benefits each period and these benefits are linked to their average lifetime earnings according to a piecewise linear function that resembles the current US Social Security program. As well, the benefits depend on the age at which individuals begin claiming them.

\subsection{Timeline}

At the beginning of each period, after observing their current idiosyncratic labor shocks and their exogenous bequest, households make their labor supply decisions and rent capital to firms. They also purchase the home input and rent housing for the current period. At this point, market production takes place. Home production also takes place using labor, home input, and housing. After production, households receive factor payments and make their consumption and asset allocation decisions. At the end of the period, capital and housing depreciate and uncertainty about early death is revealed. Accidental bequests from those who die early are distributed to new agents in the following period to first satisfy an exogenous beginning-of-period asset position, and if funds are left over, they are distributed to the other agents in the economy.

\subsection{The Household's Problem}

In a stationary equilibrium, the interest rate is constant at $r$ as is the wage rate $w$ per efficiency unit of labor. The household's state variables are given by $\left(t, a, \varepsilon, y, t_{r}\right)$, which denote the agent's current age $(t)$, financial assets $(a)$, labor productivity in the current period $(\varepsilon)$, average lifetime earnings $(y)$ and retirement age $\left(t_{r}\right)$. We have

$$
\begin{gathered}
V\left(t, a, \varepsilon, y, t_{r}\right)=\max _{\left\{c_{m}, s, d, a^{\prime}, n_{m}, n_{h}, f^{\prime}\right\}}\left\{U\left(c, 1-n_{m}-n_{h}\right)+\right. \\
\left.\beta \lambda_{t} E V\left(t+1, a^{\prime}, \varepsilon^{\prime}, y^{\prime}, t_{r}^{\prime}\right)\right\}
\end{gathered}
$$


subject to

$$
\begin{aligned}
c_{m}+\eta s+d+a^{\prime} & \leq b+(1+r) a+e_{t} \varepsilon w n_{m}-\tau \min \left(y_{\max }, e_{t} \varepsilon w n_{m}\right)+\operatorname{pen}\left(t_{r}, y\right), \\
y^{\prime} & =\left[(t-1) y+\min \left(e_{t} \varepsilon w n_{m}, y_{\max }\right)\right] / t, \text { if } t_{r}=0, \\
y^{\prime} & =y \text { if } t_{r}>0, \\
t_{r}^{\prime} & =t+1 \text { if } f^{\prime}=1 ; t_{r}^{\prime}=0 \text { if } f^{\prime}=0, \\
c_{m} & \geq 0, s \geq 0,0 \leq n_{m}, n_{h} \leq 1, a^{\prime} \geq-e_{t+1} \underline{\varepsilon}^{\prime} w,
\end{aligned}
$$

where $\operatorname{pen}\left(t_{r}, y\right)$ is the pension after retirement and it depends on the retirement age and the average lifetime earnings at the time of retirement, and $f^{\prime}$ indicates the retirement decision. In any sub-period, an agent's resources depend on asset holdings, $a$, labor endowment, $e_{t} \varepsilon$, or pension, pen $\left(t_{r}, y\right)$, and received bequests, $b$. Note that agents receive a pension only after claiming Social Security and even after that, they can still work and are subject to the payroll tax. The composite consumption good $c$ is defined as in equation (3), and the home-produced good is defined as in equation (1) using current period housing $s$, home input $d$, and home hours $n_{h}$ as inputs. Average Social Security earnings accumulate according to equation (10) if the agent has not claimed any Social Security benefits.

A formal definition of a stationary equilibrium that includes market clearing conditions is provided in Appendix A. The model is solved numerically. Appendix B describes the computation algorithm in greater detail.

\section{Calibration}

We choose the parameters of our model in two steps. In the first step, we pick parameters that are based on economic statistics from the data as well as choosing parameters, such as relative risk aversion, that are consistent with the literature. In the second step, we jointly estimate the remaining parameters that minimize a loss function based on the difference between certain model and aggregate moments calculated from data on households' time use and consumption. The calibrated parameters and the statistics that generate them are given in Table 1 and the estimated parameters are given in Table 2 . Table 3 indicates how close the model moments match the data moments. ${ }^{8}$ Given our estimated parameters, we indicate that the model also captures life cycle profiles of labor and both market and nonmarket consumption.

\footnotetext{
${ }^{8}$ Though our model is exactly identified, because the problem is highly nonlinear, we are not able to match all the target moments exactly.
} 


\subsection{First-Stage Calibration}

The model period is two years. ${ }^{9}$ Each person enters the model at age 24 . The maximum life span $T$ is 90 . Figure 1 , panel $\mathrm{b}$, shows the $\lambda_{t}^{\prime} \mathrm{s}$, the vector of conditional survival probabilities. We use the mortality probabilities in 2000 weighted by gender from the Social Security Administration life tables.

We calibrate the production parameters according to the National Income and Product Accounts and the Fixed Assets Tables for the years 1957-2007. The parameter $\alpha$ is the share of income that goes to the nonresidential stock of capital and is set at 0.24. This capital share is lower than in many real business cycle calibrations because housing is not part of our model's capital stock. We set $\delta^{k}$ to 0.09 and $\delta^{h}$ to 0.01 , within the range of those used in the literature. The interest rate on capital net of depreciation, $r$, is set to 0.05 . The implied capital-output ratio is 1.714 .

The deterministic age profile of the unconditional mean of labor productivity, $e_{t}$, is taken from French (2005) and is shown in the top panel of Figure $1 .^{10}$ The labor-efficiency profile is hump-shaped, with a peak at age 50. The persistence $\rho_{\varepsilon}$ and variance $\sigma_{\varepsilon}^{2}$ of the stochastic productivity process are 0.977 and 0.014 , respectively (French 2005). The variance of the initial distribution of productivity is 0.38 (Huggett 1996). For simplicity, we assume that the labor efficiency profile for home production is constant.

The Social Security earnings cap $y_{\max }$ is 2.47 . The retirement benefit at age 66 is calculated to mimic the Old Age and Survivor Insurance component of the Social Security system:

$$
\operatorname{pen}(\widetilde{y})=\left\{\begin{array}{ll}
0.9 \widetilde{y}, & \widetilde{y} \leq 0.2 ; \\
0.18+0.32(\widetilde{y}-0.2), & 0.2 \leq \widetilde{y}<1.24 ; \\
0.5128+0.15(\widetilde{y}-1.24), & 1.24 \leq \widetilde{y}<y_{\text {max }} \\
0.6973, & \widetilde{y} \geq y_{\max } .
\end{array}\right\}
$$

The bend points and Social Security earnings cap, expressed as fractions of average earnings, and marginal rates are from Huggett and Ventura (1999). If a household retires at the age of 62 , it receives 75 percent of the full pension, at age 64 , it receives 87 percent, at age 66, it receives the full pension, at age 68 it receives 1.16 percent, and it receives 1.32 percent if retirement is at any age greater than or equal to 70 .

The parameter $\zeta_{1}$ pins down the elasticity of substitution between housing services and the home input. We set this parameter to the value identified in Dotsey, Li, and

\footnotetext{
${ }^{9}$ Given the model period, we adjust parameters in the model accordingly. We report parameters at annual frequency, unless stated otherwise.

${ }^{10}$ We scale up the profile by a factor of 30 to target an economy-wide income of $\$ 31,000$, the average income calculated from CEX after taking out the family size, marital status, and interview year effect.
} 
Yang (2010) because we no longer model owner-occupied housing in the current model. As a result, the consumption of housing and home input will always be in constant proportion, and therefore, the parameter $\zeta_{1}$ is not identifiable.

We take the risk aversion parameter, $\gamma$, to be 1.5, from Attanasio et al. (1999), and Gourinchas and Parker (2002), who estimate it from consumption data. The initial distribution over state variables (wealth, initial labor productivity level) for households of age 24 is calculated using data from the Survey of Consumer Finances (2001, 2004, and 2007) for households whose heads are between ages 23 and 26. Accidental bequests are first distributed to new agents to reproduce the distribution of capital endowments, which implies most households start with close to zero wealth. The rest of the bequests, if there are any, are distributed evenly to all living agents, which endogenously determines $b$.

\subsection{Second-Stage Estimation}

For the second-stage estimation, we use the National Income and Production Accounts and two micro data sets on households' consumption expenditures and time use, the Consumer Expenditure Survey (CES) and the American Time Use Survey (ATUS). Dotsey, Li, and Yang (2010) provide detailed information on these two data sets and the classification of consumption and time use into different categories. To reiterate, we follow the tradition of Reid (1934) and separate nonmarket time into pure leisure and home hours, where home hours comprise time spent on activities performed at home to produce goods and services that can also be purchased in the market and are, for the most part, not enjoyable to produce (Table 1 of Dotsey, Li, and Yang 2010). ${ }^{11}$ In particular, we define home hours as time spent doing house work, house work service, shopping, pet care, car care, child care, adult care, shop search, car service, child care service and professional service. We define market hours as the time the head of the household spends working, job searching, and commuting. We treat the remaining time as leisure.

For consumption, we include in our market good food away from home, alcohol, tobacco, apparel, other lodging, fees and admissions for entertainment, and related equipment such as televisions, radios, sound systems, pets, toys, and playground equipment, reading, and personal care. We also include education expenses and out-of-pocket medical expenses in the market good, but our results are robust to the exclusion of these

\footnotetext{
${ }^{11}$ In particular, Reid defines home production as "those unpaid activities which are carried on, by and for the members, which activities might be replaced by market goods, or paid services, if circumstances such as income, market conditions, and personal inclinations permit the service being delegated to someone outside the household group." (Reid 1934, p.11)
} 
categories. We include in our home input food cooked at home, household operations, household furnishings and equipment, utilities, fuels, and public services. We pro-rate transportation expenses by travel time for home production or market production that we obtained from the ATUS. For housing, we use rental payments for renters, and we use homeowners' reported house value of owned residences. We then calculate the rental house size as rental payment divided by 6 percent, the value of $\eta$ in our model.

Regarding the estimated moments, we deviate from Dotsey, Li, and Yang (2010), who use differences across home owners and renters in estimation, and instead choose to match moments on consumption and time use calculated for the young (those between ages 24 and 49) and the old (those between ages 50 and 80). ${ }^{12}$ Specifically, we choose the parameters, $\beta, \tau, \zeta_{i}(i=2,3,4), \omega_{i}(i=1,2,3,4)$, based on the following moments: $K / Y$, Social Security budget balance, the economy-wide consumption of the home input relative to housing stock, the average home input of both the young and the old, and their respective average market hours and home hours. We also normalize the average expenditure by economy-wide income. Thus, we simultaneously choose these 9 parameters to match the 9 selected moments as summarized in Table 3. The moments basically involve various expenditure income ratios as well as moments pertaining to the use of time. It is important to note that although our procedure jointly uses 9 moments to identify 9 parameters, certain moments are relatively more responsible for pinning down the shares and elasticities in the CES aggregates.

For example, $\beta$ is largely determined by $K / Y$ and $\tau$ is mainly pinned down by Social Security budget balance. The three elasticity parameters $\left(\zeta_{i}, i=2,3,4\right)$ play crucial roles in determining households' supply of labor to different activities and consumption of different goods. Given $\zeta_{1}$, which is taken from our 2010 paper, we calibrate $\omega_{1}$ by matching the ratio of home input to housing size. The relative amount of time spent in home production across the young and the old helps to pin down $\zeta_{2}$ and $\omega_{2}$. The difference in consumption of the market good across young and old helps to pin down $\zeta_{3}$ and $\omega_{3}$. Finally, the difference in the relative time worked in the marketplace by each of these cohorts is useful for identifying $\zeta_{4}$ and $\omega_{4}$ because they help determine leisure. However, the estimation is more complicated than indicated by the discussion here and is not totally driven by one set of moment differentials driving one pair of elasticity and share parameters.

\footnotetext{
${ }^{12}$ The reason for this departure is that we no longer have owner-occupied housing in the current set-up.
} 


\subsection{Resulting Life-Cycle Profiles of Labor Supply and Con- sumption}

Though the target moments are somewhat different, the second-stage calibrated parameters are similar to those in Dotsey, Li, and Yang (2010). The home input and housing are Hicksian substitutes in the productions of the composite home good, while the composite of home input and housing exhibits strong complementarity with home hours in home production. The market good and home good, on the other hand, are substitutes. Finally, the final composite consumption good made up of the market good and home good is substitutable with leisure in households' utility. The existing literature on home production has largely lumped home hours and leisure together into nonmarket hours, making the comparison with our estimates difficult. Nevertheless, there is some supporting evidence. For example, Abbott and Ashenfelter (1976) find that housing, transportation, and other services tend to be complementary with nonmarket time. Barnett (1979) estimates a model of joint goods and leisure and finds non-weakly-separable substitution between consumption and leisure. Greenwood and Hercowitz (1991) argue that to generate comovement in investments in durable goods in the market and at home one needs to have complementarity between durable goods and time in home production. McGrattan, Rogerson, and Wright (1997) estimate the residential capital to be complementary to home hours in home production. The finding that the home input and housing are complements with home hours in home production explains why after a household moves from being a two-earner family to a one-earner family, home capital typically increases, as documented in Baxter and Rotz (2009). The strong substitutability between market goods and home goods is consistent with the findings in the literature, notably McGrattan, Rogerson, and Wright (1997) and Rupert, Rogerson and Wright (2000).

We chart the simulated life-cycle hours and consumption profiles against the corresponding data profiles in Figure 2. The data profiles are created using the ATUS (2005-2007) and the CEX (2003-2006) as in Dotsey, Li, and Yang (2010). Note that the model does a reasonably good job at matching the data profiles. The supply of home hours is flat early in the life cycle and begins to rise after households reach age 55 when the market labor efficiency starts to decline. By contrast, market hours are stable untill age 50 and then decline steadily. By age 65, the average household devotes less than 10 percent of its time to market work. The consumption profiles are hump-shaped. Notice that in our model the consumption profile for the home input and housing track each other when measured as log deviations from their respective levels at age 40; thus we 
only depict the data for housing. ${ }^{13}$ Additionally, the hump shape in the consumption of the market good is more pronounced than that of housing (and by extension the home input). Thus, our model is consistent with the findings of Aguiar and Hurst (2009).

Figure 3 plots the cumulative fraction of all retirees who claim an initial Social Security entitlement at a particular age for both the model and the data. The data come from the 2008 Social Security Annual Statistical Supplement Table 6.a4. Using statistics constructed from more years does not appreciably change the chart (see Imrohoroglu and Kitao 2012). The model does a reasonably good job of matching the data profile except that the model predicts an initial entitlement age distribution that is a little flatter than the data. In other words, slightly more households claim their Social Security benefits at earlier ages in the model than in the data.

\section{Policy Analysis}

We now study the long-run effects of eliminating Social Security and the associated payroll taxes. We first report the aggregate statistics, the life-cycle effects, and then analyze the welfare implications of this reform.

\subsection{Aggregate Statistics}

Table 4 summarizes the aggregate effects of removing Social Security by comparing our benchmark economy with and without Social Security benefits. Eliminating the Social Security pension has three effects on household savings. The first is the standard overlapping generations result that reducing pay-as-you-go Social Security increases saving and the capital stock. Second, reducing the pension is similar to reducing the annuity for old age households. Given an uncertain life span, households also save more to insure that they have adequate wealth late in life. Third, the pension partly acts as a redistribution or insurance mechanism, with poor households receiving more payments than they otherwise could afford. Reducing the pension payment impels these households to save more for themselves.

When both aggregate capital $\mathrm{K}$ and aggregate labor $\mathrm{L}$ increase, the change of $r$ and $w$ depend on the relative increase of $K / L$ as $r=\alpha(K / L)^{\alpha}-\delta^{k}$. According to our analysis, eliminating the Social Security system leads to a decline of 60 basis points in the equilibrium interest rate as households save more through the private market for their retirement and to insure against idiosyncratic income shocks. Accordingly, the aggregate

\footnotetext{
${ }^{13}$ Since the data profile for home input is more humped than that for housing, our model profile is actually a better fit for home input.
} 
capital output ratio increases to 1.79 from 1.71, an increase of over 5 percent and the wage rate increase by 1.47 percent. The increase in the wage rate and the reduction in the payroll tax leads to an increase in market hours of over 6 percent compared to the benchmark with Social Security. Overall, households are also wealthier and the wealth effect attenuates the increase in hours worked.

In the absence of Social Security, households are wealthier, and thus they consume more. However, the increase in consumption varies substantially across goods. The fall in the interest rate reduces the relative cost of housing by directly lowering rents. Aggregate housing consumption rises by more than 17 percent in relation to the benchmark. ${ }^{14}$ Households also substitute cheaper housing for home input. As a result, the 0.56 percent increase of the home input is much smaller than the increase in housing services. Households' consumption of market goods also increases, and the 3.44 percent increase is larger than the increase in home input, but much smaller than the increase in housing services. The increase in the consumption of housing services induces households to increase their supply of home hours because housing services and home hours are complements in home production. However, the increase in market hours has an offsetting effect on the supply of home hours that largely offsets the upward pressure from higher housing consumption. On balance, households' supply of home hours moves up by a slight 0.43 percent. Leisure, by comparison, falls by close to 1.45 percent. Aggregate effective labor increases less than total market hours, indicating that less productive individuals increase labor supply more than productive ones.

\subsection{Life-Cycle Effects}

We plot the life-cycle profiles of market hours and home hours before and after Social Security reform in Figure 4. Social Security reform increases the return to supplying market hours when there is no longer a payroll tax and the wage rate is higher. The reform also increases hours spent in home production when households are young as the lower interest rate makes housing more affordable and the complementarity of the home input results in more home input being purchased as well. Older households are affected less because they are relatively more productive and using home hours is relatively expensive for them. The absence of Social Security benefits also gives older households additional incentives to work in the market. The end result is that households younger than 40 reduce their market hours and increase their home hours. By contrast, households older than 50 increase their market hours and reduce their home hours.

In terms of consumption, the lower interest rate enables households to choose a

\footnotetext{
${ }^{14}$ This relatively large effect is also found by Chen (2010).
} 
much flatter consumption profile over the life cycle. Note that in our economy, for a given interest rate the ratio of the consumption of home input to housing is constant among households. Consequently, the profiles of housing and home input, measured as log deviations from consumption at the beginning of the life cycle, track each other perfectly. The reduction in the consumption hump is more evident in home input and housing than in market consumption. This is because in our model, home hours are complements to the aggregate of home input and housing. As hours working at home increase for the young, so do housing and home input, effectively flattening the associated life-cycle profiles. This highlights the importance of modeling the interaction between consumption and leisure through home production.

\subsection{Welfare Implications}

In this section, we explore the long-run welfare implications of Social Security reform, i.e., our analysis does not take into account the transition cost associated with the move from one steady state to another. Following McGrattan, Rogerson, and Wright (1997), the welfare effects are measured by the percentage changes in market consumption that makes an unborn household (before the realization of all state contingencies) indifferent between the two steady states holding the amount of leisure constant. We follow their procedure because market consumption is the only consumption good that is common across the various models. By this measure, we find that aggregate welfare increases by 19.06 percent after the complete elimination of Social Security.

Social Security provisions affect welfare in several ways. First, because of the lack of a perfect annuity market, Social Security benefits provide partial insurance against mortality risk. Second, since the benefits of Social Security is not linearly correlated with the contribution, Social Security benefits redistribute wealth among retirees and thus provide partial risk sharing against income uncertainty. Both effects are welfare improving. Social Security provisions, especially the associated payroll taxes, however, are also distortionary. Households reduce labor supply in the presence of the payroll tax, leading to reduced income. This is particularly costly to those who are credit constrained. In our analysis, as in the existing literature, the distortionary effects outweigh the welfare-improving effects.

To explore the distributional effects of the reform, we group households according to their initial market labor productivities at age 24. Interestingly, the welfare gains of eliminating Social Security benefits are negatively correlated with the initial productivities. The least productive households receive the most gain (34.07 percent) and the most productive households receive the least gains (4.38 percent). The welfare gains for 
the other three groups are 26.64 percent,18.63 percent, and 12.54 percent, respectively. These results suggest that the distortionary effects associated with payroll taxes and the lower wages associated with the existence of Social Security wages outweigh the distributional effects, and that these distortions are particularly acute for those individuals who face a borrowing constraint, namely, the least productive households.

\section{Investigating the Role of Home Production}

To isolate the role that home production plays in influencing the results associated with our policy analysis, we reestimate a version of our benchmark economy without home production. We do so by setting the weight on home hours, $1-\omega_{2}$, to zero. Doing so implies that the period utility function collapses into a multi-level constant elasticity of substitution formulation over the different types of consumption goods (market good, home input, and housing) and leisure. As a result, the consumption of housing, the home input, and the market good will always be in constant proportion, although the proportion changes with interest rates. We can no longer separately identify the parameter $\zeta_{3}$ that governs the relative consumption of home good and market good without the presence of home production. For consistency, we fix $\zeta_{3}$ at the value calibrated in the benchmark.

\subsection{Calibration}

We also choose the same first-stage parameters as in the benchmark, because we are matching the same aggregate moments that determine these parameters. We rescale the labor efficiency profile to arrive at the same economy-wide average income as in the benchmark. Table 5 reports the estimated parameters in the second stage. The weight $\omega_{1}$ is the same as that in the benchmark model because it is only affected by one moment: the economy-wide consumption of home input relative to housing services.

By setting $\omega_{2}$ to 1 , we effectively raise the marginal productivity of home input and housing in the production of home goods because the home production function that exhibits decreasing returns in the aggregate of home input and housing in the benchmark now displays constant returns. In other words, for any given amount of housing and home input, there is now a greater supply of the home good. To match the same share for market consumption, we need to raise the weight on market consumption (higher $\left.\omega_{3}\right)$. Similarly, because we lump home hours into leisure, we need a lower weight on consumption $\omega_{4}$ to increase households' demand for leisure.

Although not shown, the match of the model moments with their data counterparts is 
on average somewhat worse than in the benchmark model. This is also evident from the chart on life cycle profiles (Figure 5). Obviously, we completely miss the life cycle profile on home hours. The profile on housing/home input is also worse than the benchmark with the profile touching the two-standard deviations upper boundary during middle ages and exceeding the lower boundary after age 78 .

\subsection{Policy Implications}

We conduct the same policy experiment as in the benchmark by eliminating Social Security benefits. We report changes in the aggregate statistics in Table 6 and changes in life cycle profiles in Figure 6. For comparison, we also list in Table 6 the corresponding changes for the benchmark economy.

After eliminating Social Security benefits, households again compensate by increasing their savings for retirement and the increase is more than that in the benchmark experiment as households cannot rely on home production to help make up income shortfalls. For the same reason, households also work much harder in the market after the reform. The end result is a lower equilibrium interest rate and a higher wage. The drop in the interest rate is less than that in the benchmark experiment, and correspondingly, the increase in the effective wage rate is also lower because labor increases more than that in the benchmark model. Labor supply in this model is more elastic than that in the benchmark model. This is because in the benchmark model, the increase of labor supply is constrained by the increase in home hours caused by the upward pressure from higher housing consumption.

In terms of consumption, the consumption of housing services increases by much more than in the benchmark even though the interest rate does not fall as much. In our benchmark economy, because housing complements home hours in home production, the consumption of housing is to some extent constrained by the supply of home hours. For example, when wages are high, households will want to supply more market hours and reduce their home hours, which in turn puts downward pressure on housing consumption. Without home production, this channel no longer operates and the demand for housing is more interest elastic. A similar argument explains the larger increase in home input in the model without home production. Changes in the aggregate consumption of the market good are much closer across the two economies.

Comparing the consumption and time use profiles between the young and old, the lower new equilibrium interest rate still flattens both the consumption and the hours profiles, but not by as much as in the benchmark experiment. Notice that the consumption profiles for the home input, housing, and market consumption track each other 
when measured as log deviations from their respective levels at age 24. Contrary to the benchmark model, the reduction in the consumption hump is the same among all three consumption goods.

Finally, using the same welfare metric as in the benchmark experiment, we find that eliminating Social Security benefits leads to an increase in welfare of 16.06 percent, which is 3 percentage points or roughly a 15 percent smaller effect than in the benchmark experiment. In our benchmark model with home production, households use home production as an additional means to smooth consumption or to make up an income shortfall in old age. Thus the benefit of Social Security is smaller, while the costs of financing it are higher. This mechanism also explains the differences in welfare gain for households with different initial market labor productivities: Ranked by their initial market labor productivity from low to high, the welfare gains for the groups are, respectively, 23.59 percent, 19.84 percent, 15.60 percent, 12.06 percent, and 5.12 percent. Those with low initial productivity, for whom Social Security serves as an important source of insurance, benefit much less from the reform than in the benchmark. Thus, the inclusion of home production has important distributional implications for the steady-state welfare gains associated with the elimination of Social Security.

\section{Comparison with the One-Good Economy}

Our analysis so far indicates that home production plays an important role in matching the life cycle profiles of households' market and nonmarket activities and an economy without home production biases down the welfare gains of eliminating Social Security benefits by 3 percentage points. Traditionally, however, the literature on Social Security reforms has exclusively focused on a one-good economy. To facilitate the comparison of our economy with the literature, we now investigate an economy where households consume only one good, which is a sum of the market good, the home input, and housing services as defined in our benchmark economy. We, however, maintain the functional form of constant elasticity of substitution between this aggregate consumption and leisure for the period utility.

Given that housing capital is now part of the aggregate capital stock, the new capital output ratio is 3.302 and the average depreciation rate is 0.047 . The capital share in production $\alpha$ is now 0.321 in order to match the 5 percent interest rate that we used to calibrate the benchmark model. We rescale the labor efficiency profile to arrive at the same economy-wide average income as in the benchmark. We reestimate the discount factor $\beta$, payroll tax rate $\tau$, the elasticity parameter for consumption and leisure $\zeta_{4}$, and the weight on consumption $\omega_{4}$. The elasticity parameter for consumption and leisure 
$\zeta_{4}$ and the weight on consumption $\omega_{4}$ are set to 1.421 and 0.075 , respectively, to match the average market hours for the old (0.102) and the young (0.212). Note the calibration for $\zeta_{4}$ and $\omega_{4}$ is very similar to the economy without home production, but with various consumption goods. The model implied market hours are 0.112 for the old and 0.200 for the young, roughly matching the empirical moments. As shown in Figure 7, the model also does a fairly good job at matching the market labor profile. It, however, generates too large a hump in the consumption profile when compared to the data. ${ }^{15,16}$

We then conduct the same policy experiment as in the other two models. We report the aggregate statistics in Table 6 and chart the life-cycle consumption and labor-supply profiles before and after the policy change in Figure 8. As expected, aggregate capital increases substantially by 15.63 percent, much larger than that in our benchmark economy and the alternative economy that differentiates between consumption goods but with no home production. In the two previous models with housing as a consumption good, the increase of total wealth after the reform is also very high (13.27 percent and 15.64 percent, respectively). However, since most of the increase goes to housing, the increase of capital is more moderate, and as a result, the decrease in the interest rate and the increase in the wage rate are also smaller. The substantial increase of wage rate in the one-good economy also explains why market labor supply increases in response to a zero payroll tax rate by 4.18 percent, a rate larger than the increase in the benchmark and the alternative economy without home production. Over the life cycle, because of a lower equilibrium interest rate, both the labor supply and consumption profiles flatten out. The consumption profiles behave similarly to those of the market good defined in the previous two economies.

Finally, the welfare gains of eliminating Social Security benefits drop to 10.40 percent, a whole 6 percentage points lower than achieved in the economy without home production, and almost 9 percentage points lower or roughly half as much as the welfare gains in the benchmark economy. The driving force for this result is that households need to save more in this economy, for precautionary reasons and for old age. Social Security, which helps make up for the shortfall in savings, therefore, is more valued and the welfare loss due to its absence compensates to a greater degree the gain from removing distortionary Social Security taxes. Ranking households by their initial market labor productivity from lowest to highest, the welfare gains are 16.89 percent, 14.43 percent, 11.49 percent, 8.92 percent, and 3.91 percent, respectively. Again, the gains are much smaller compared with the benchmark economy and the alternative economy without

\footnotetext{
${ }^{15}$ The empirical profile for aggregate consumption is generated using the same methodology as in the benchmark.

${ }^{16}$ Imrohoroglu and Kitao (2009) generate an even larger hump in consumption, which peaked much later than in the data.
} 
home production for households with lower initial labor productivity.

\section{Conclusion}

We study the aggregate economic and welfare effects of Social Security reform in an environment with home production technology and explicit modeling of consumption of different goods. We show that such reform will not only have aggregate repercussions, but also differentially impact the demand for various goods depending on the degree of substitutability between home production and market work for each particular good. There is an extensive literature that studies possible reform of the Social Security system. Such studies, however, abstract from the key role of home production in the household sector and treat all consumption goods the same. We show that studies that abstract from these features, and which in turn do not match key life-cycle moments and profiles, may be subject to error. Importantly, the welfare bias can be as much as 10 percentage points. Interesting extensions of the paper include modeling relative prices of different goods and introducing aggregate shocks to study what role home production plays in helping households smooth consumption over the business cycle. We leave these to future research.

\section{Appendix}

\section{Appendix A. Definition of the Stationary Equilibrium}

We focus on the stationary equilibrium of the economy where factor prices and agent distribution over the state space are constant over time. Each agent's state is denoted by $x$. Let $S$ denote the aggregate housing stock available for renting, $D$ the aggregate stock of home input, $C_{m}$ the aggregate consumption of the market good, $I_{h}$ the aggregate investment on housing, $I_{k}$ the aggregate investment on physical capital.

Definition 1. A stationary equilibrium is given by government policies including tax rate $\tau$, and pension pen $\left(t_{r}, y\right)$; an interest rate $r$ and a wage rate $w$; price of rental housing $\eta$; value functions $V(x)$; allocations $c_{m}(x), a^{\prime}(x), d(x), s(x), n_{m}(x)$, $n_{h}(x), f^{\prime}(x)$; bequest $b$; and a constant distribution of people over the state variables $x, v(x)$, such that the following conditions hold:

(i) Given the government policies, the interest rate, the wage, price of rental housing, and the expected bequest, the value functions and allocations solve the above-described maximization problem for a household with state variables $x$. 
(ii) $v($.$) is the invariant distribution of households over the state variables.$

(iii) The price of each factor is equal to its marginal product.

$$
\begin{aligned}
r & =F_{1}^{m}(K, L)-\delta^{k}, \\
w & =F_{2}^{m}(K, L) .
\end{aligned}
$$

(iv) The expected bequest is consistent with the actual bequest left

$$
\int b v(d x)+\int_{t=0}(a(1+r)) v(d x)=\int\left(1-\lambda_{t}\right)\left[(1+r) a^{\prime}\right] v(d x) .
$$

(v) No arbitrage condition holds

$$
\eta=r+\delta^{s}
$$

(vi) Government budget is balanced at each period

$$
\tau \int \min \left\{\varepsilon e_{t} w n_{m}, y_{\max }\right) v(d x)=\int \operatorname{pen}\left(t_{r}, y\right) v(d x) .
$$

(vii) All markets clear.

$$
\begin{aligned}
S & =\int s v(d x), \\
D & =\int d v(d x), \\
K & =\int a v(d x)-S, \\
C_{m} & =\int c_{m} v(d x), \\
L & =\int \varepsilon e_{t} n_{m} v(d x), \\
I_{k} & =K^{\prime}-\left(1-\delta^{k}\right) K, \\
I_{h} & =S^{\prime}-\left(1-\delta^{h}\right) S \\
F^{m}(K, L) & =C_{m}+D+I_{k}+I_{h} .
\end{aligned}
$$

\section{Appendix B: Computation of the Model}

To compute the steady state of our model, we first discretize the income process into 5 points. The state space for average lifetime earnings and asset holdings is discretized into unevenly spaced grids. The upper bounds on the grids are chosen to be large enough so that they do not constitute a constraint on the optimization problem. We chose 20 grid points for the asset variables and 15 for the average lifetime earnings. The choice 
variables are searched over 150 grid points for assets, 100 points on market hours, and continuous for other variables. We use linear approximation to approximate valuation functions for the points not on the state grids.

We solve for the steady-state equilibrium as follows:

1. Make an initial guess of interest rate $r$, the wage rate $w$ and tax rate $\tau$.

2. Guess the size of accidental bequests.

3. Set the value function after the last period to be 0 and solve the value function for the last period of life for each of the points of the grid. This yields policy functions and value functions in the last period.

4. By backward induction, repeat step 3 until the first period in life.

5. Compute the associated stationary distribution of households by forward induction using the policy functions starting from the known distribution over types of age.

6. Check whether the associated accidental bequests are consistent with the initial guess. If so, continue to step 7 . If not, go back to step 2 and update accidental bequests.

7. Check whether market clearing conditions hold, and whether the government budget is balanced. If so, an equilibrium is found. If not, go to step 1 and update the initial guess. 

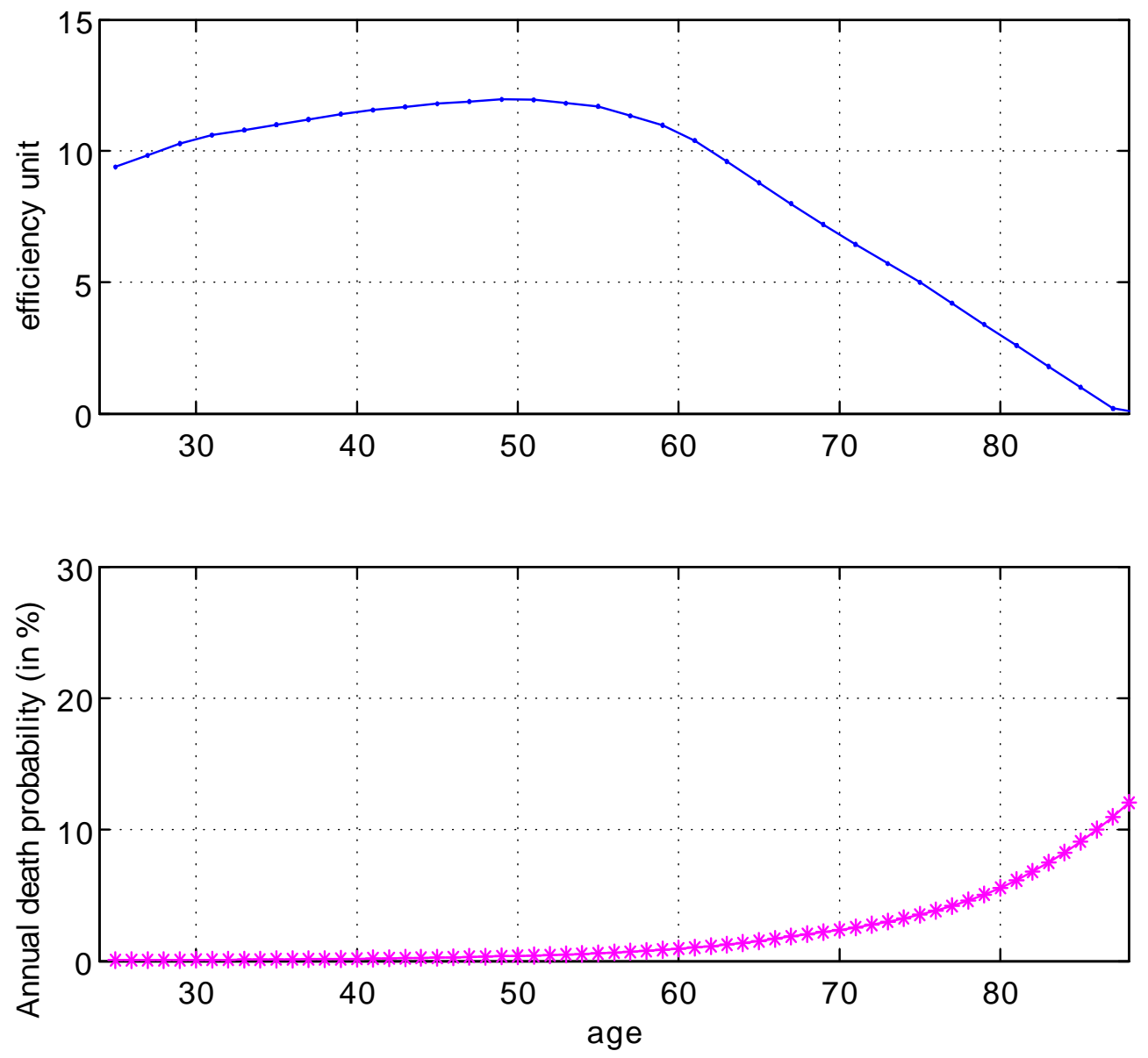

Figure 1: Exogenous Life-cycle Profiles 

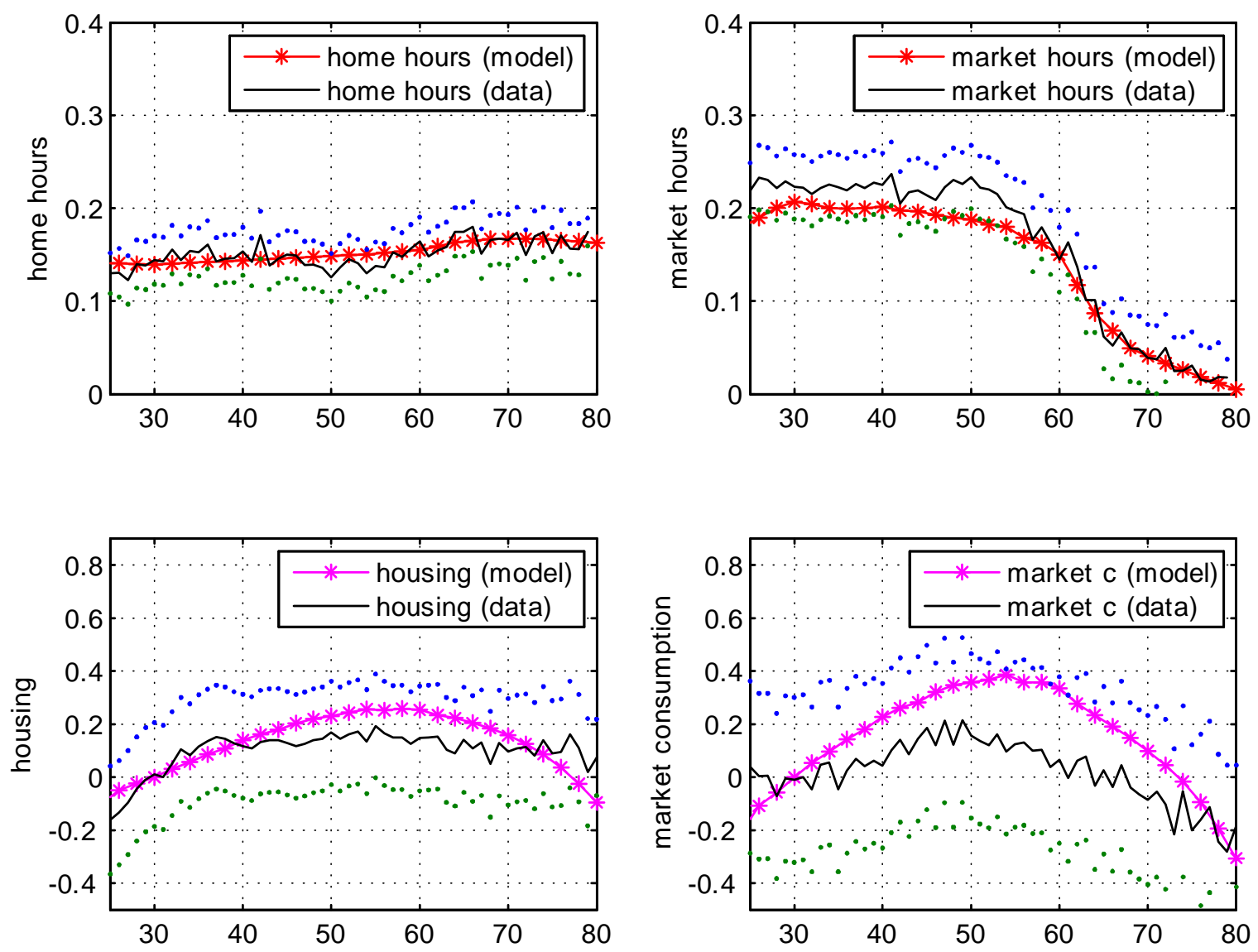

Figure 2. Life-cycle Labor Supply and Consumption Profiles - benchmark without home production (the dotted lines represent the two-standar- deviation error band) 


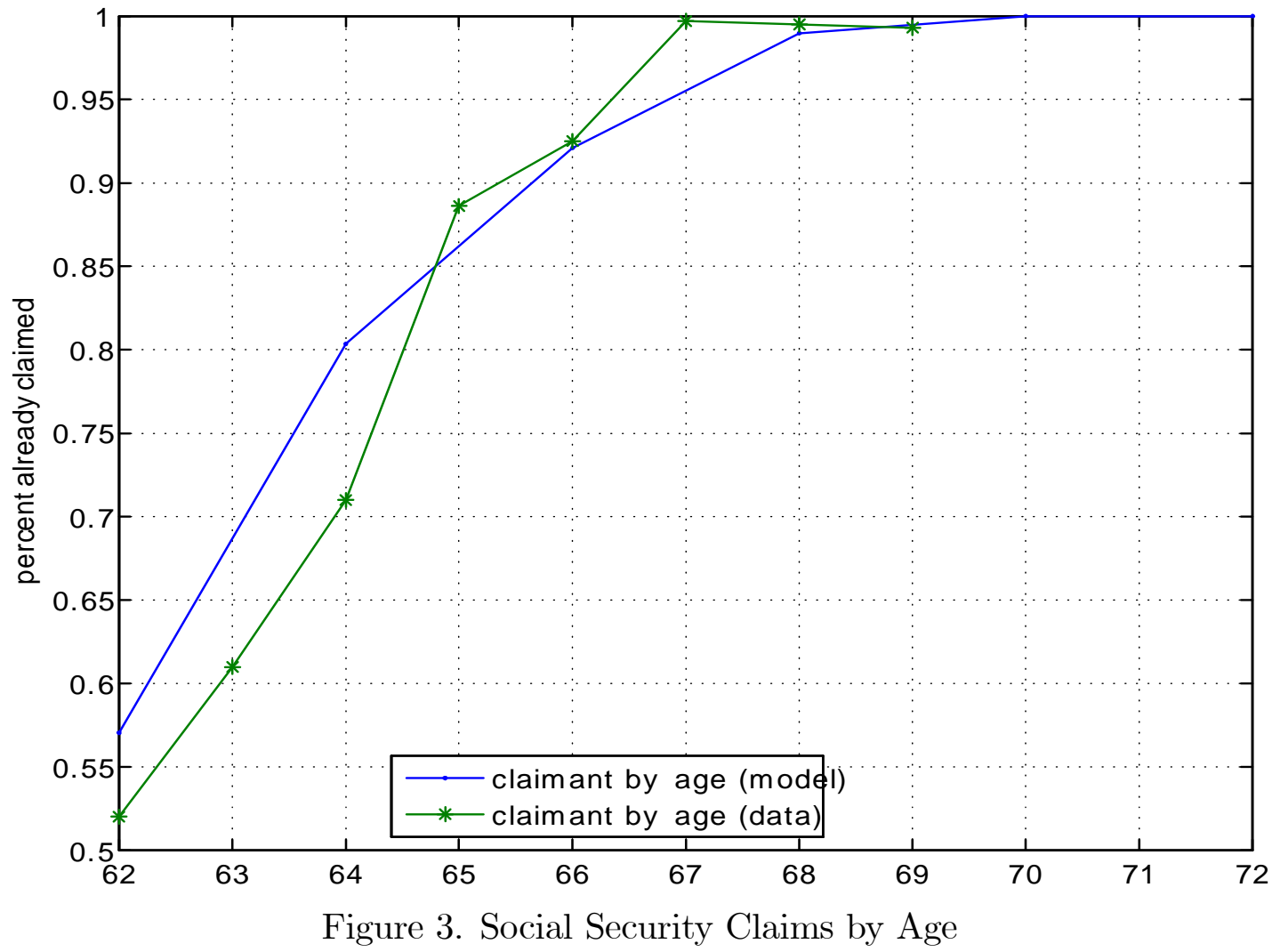



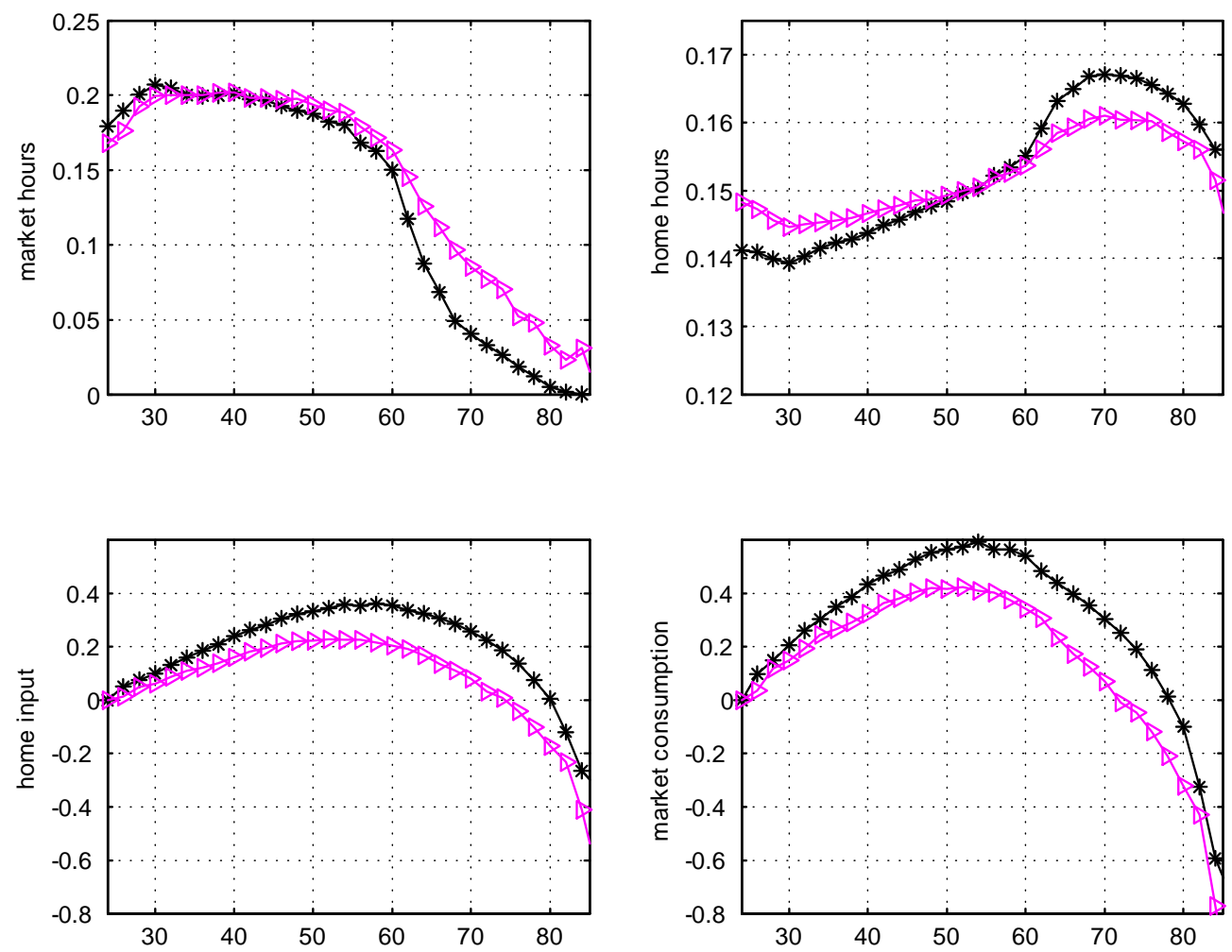

Figure 4. Life-cycle Profiles of Labor Supply and Consumption with Home Production (-*: benchmark with Social Security Benefit; - $\triangleright$ : benchmark without Social Security Benefit) 

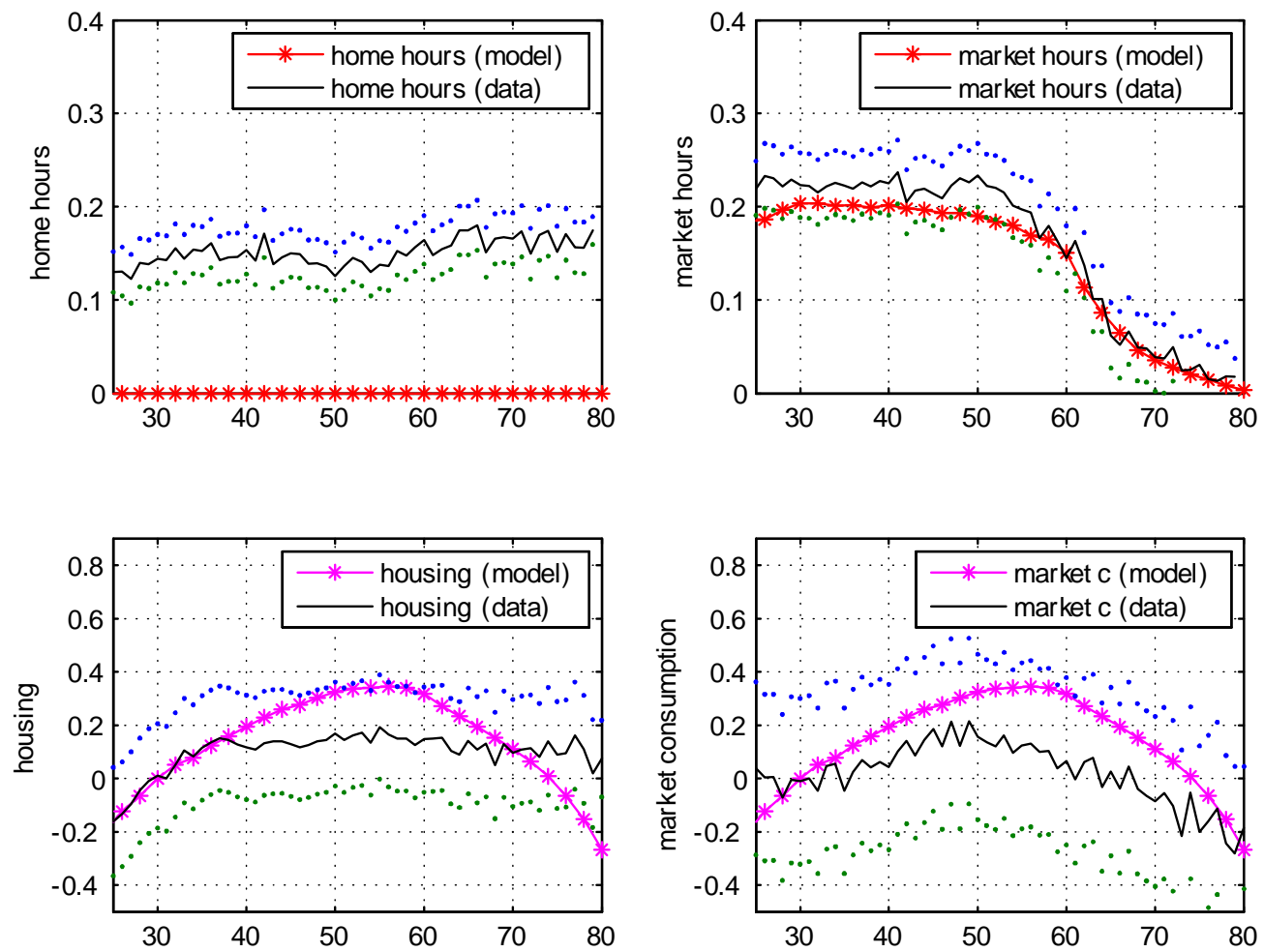

Figure 5. Life-cycle Labor Supply and Consumption Profiles - benchmark without home production (the dotted lines represent the two-standard-deviation error band) 

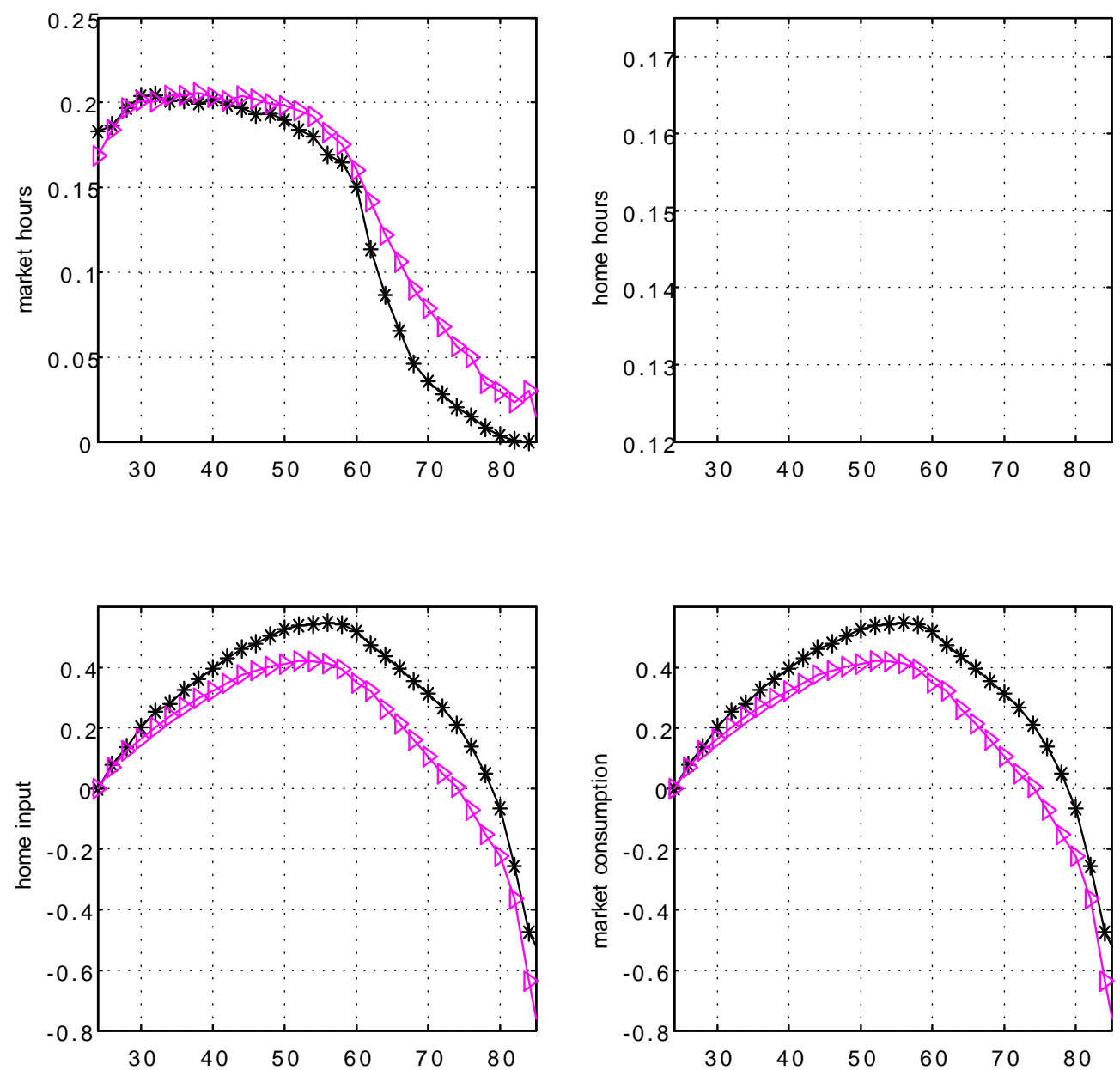

Figure 6. Life-cycle Profiles of Labor Supply and Consumption without Home Production (-*: with Social Security benefits; - $\triangleright$ : without Social Security benefits) 

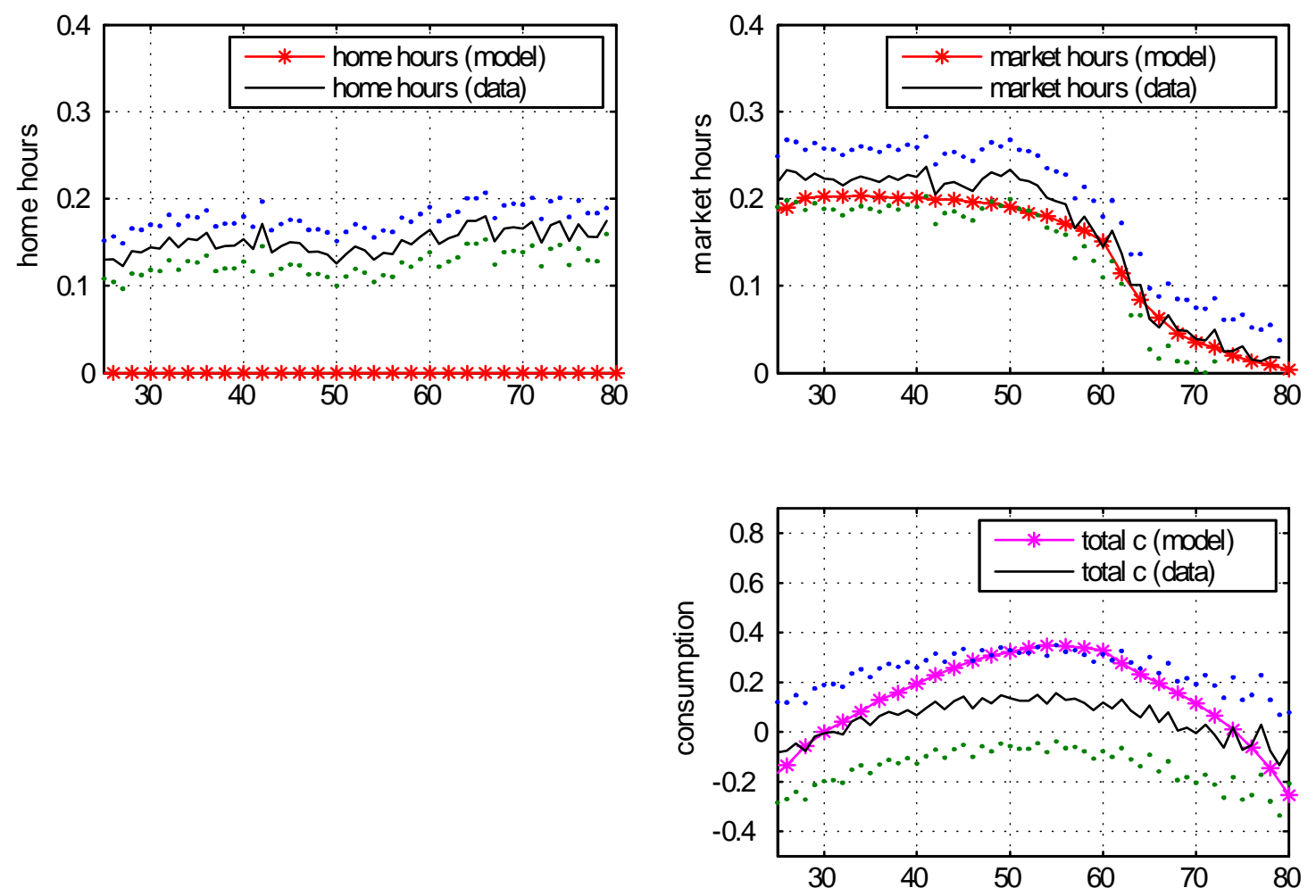

Figure 7. Life-cycle Profiles of Labor Supply and Consumption in the One-good Economy (the dotted lines represent the two-standard-deviation error band) 

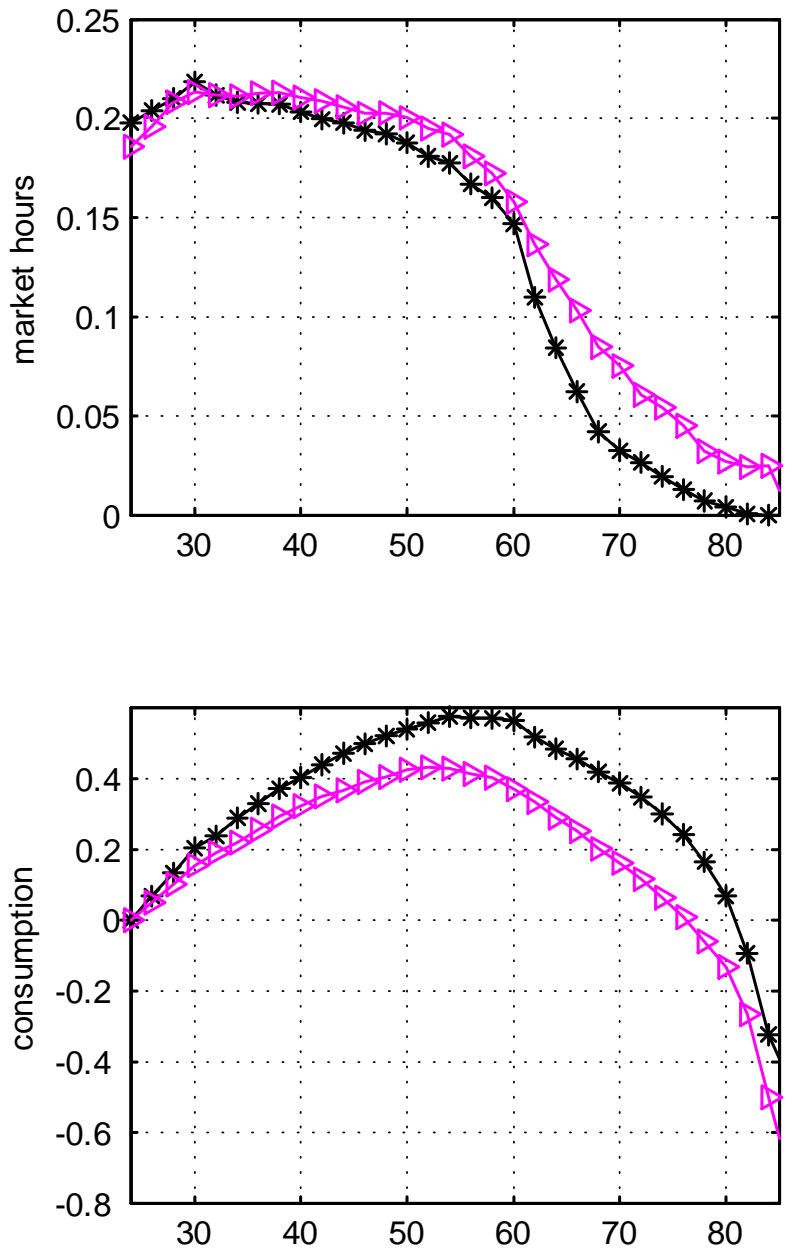

Figure 8. Life-cycle Profiles of Labor Supply and Consumption in the One-good Economy (-*: with Social Security benefits; - $\triangleright$ : without Social Security benefits) 
Table 1. Calibration According to the Data and the Literature

\begin{tabular}{|c|c|c|c|}
\hline Parameters & & Value & Source \\
\hline \multicolumn{4}{|c|}{ Demographics } \\
\hline$T$ & maximum life span & 90 & \\
\hline$\lambda_{t}$ & survival probability & Fig. 1 & $\begin{array}{l}\text { Social Security Administration } \\
\text { Life Tables }\end{array}$ \\
\hline \multicolumn{4}{|l|}{ Technology } \\
\hline$\alpha$ & capital share in National Income Accts. & 0.240 & authors' calculation \\
\hline$\delta^{k}$ & annual depreciation rate of capital & 0.090 & authors' calculation \\
\hline$\delta^{h}$ & annual depreciation rate of housing & 0.010 & authors' calculation \\
\hline$\delta^{d}$ & biannual depreciation rate of home input & 1.000 & authors' calculation \\
\hline \multicolumn{4}{|l|}{ Endowment } \\
\hline$e_{t}$ & age-efficiency profile & Fig. 1 & French $(2005)$ \\
\hline$\rho_{\varepsilon}$ & $\mathrm{AR}(1)$ coefficient of income process & 0.977 & French (2005) \\
\hline$\sigma_{\varepsilon}^{2}$ & innovation of income process & 0.014 & French $(2005)$ \\
\hline \multicolumn{4}{|c|}{ Government policy } \\
\hline $\operatorname{pen}\left(t_{r}, y\right)$ & Social Security benefit & & see text \\
\hline \multicolumn{4}{|c|}{ home production } \\
\hline $\begin{array}{c}\zeta_{1} \\
\text { Preference }\end{array}$ & sub. betw. d and h & 1.369 & Dotsey, Li and Yang (2010) \\
\hline$\gamma$ & risk aversion coefficient & 1.500 & $\begin{array}{l}\text { Attanasio, et al (1999), } \\
\text { Gourinchas and Parker (2002) }\end{array}$ \\
\hline
\end{tabular}

Table 2. Calibration to Match Data Moments

\begin{tabular}{clc} 
Parameters $(9)$ & Value \\
\hline$\beta$ & discount factor & 0.952 \\
$\tau$ & Social Security tax rate & 0.101 \\
$\omega_{1}$ & weight on durable & 0.734 \\
$\zeta_{2}$ & sub. betw. d and h composite and $n_{h}$ & 0.792 \\
$\omega_{2}$ & weight on d and h composition & 0.826 \\
$\zeta_{3}$ & sub. betw. market and home goods & 1.709 \\
$\omega_{3}$ & weight on market goods & 0.164 \\
$\zeta_{4}$ & sub. betw. consumption and leisure & 1.421 \\
$\omega_{4}$ & weight on consumption & 0.230 \\
\hline
\end{tabular}


Table 3. Calibration Results

\begin{tabular}{lcc} 
Moments & Model & Data \\
\hline capital output ratio (K/Y) & 1.714 & 1.714 \\
Social Security budget balance & 0.000 & 0.000 \\
home input/housing & 0.110 & 0.110 \\
The Young (between ages 24 and 49) & \\
average expenditure on home input goods/income & 0.236 & 0.245 \\
average share of home hours & 0.142 & 0.145 \\
average share of market hours & 0.212 & 0.199 \\
The Old (between ages 50 and 80) & \\
average expenditure on home input goods/income & 0.256 & 0.265 \\
average share of home hours & 0.155 & 0.157 \\
average share of market hours & 0.102 & 0.113 \\
\hline
\end{tabular}

Table 4. Aggregate Effects of Eliminating Social Security Benefits in the Benchmark Economy

\begin{tabular}{lrr}
\hline Variable & SS Benefits & $\begin{array}{l}\text { without SS Benefits } \\
\text { (changes relative to the init. steady state) }\end{array}$ \\
\hline Social Security tax rate $(\tau)$ & 0.101 & $0.000(-100 \%)$ \\
interest rate $(r)$ & 0.050 & $0.044(-12.640 \%)$ \\
wage $(w)$ & 0.724 & $0.735(1.470 \%)$ \\
capital output ratio $(K / Y)$ & 1.714 & $1.795(4.729 \%)$ \\
aggregate capital $(\mathrm{K})$ & 62.475 & $68.271(9.278 \%)$ \\
aggregate labor $(\mathrm{L})$ & 76.540 & $78.704(2.832 \%)$ \\
total housing/income & 1.980 & $2.319(17.114 \%)$ \\
home input/income & 0.218 & $0.219(0.560 \%)$ \\
market consumption/income & 0.571 & $0.591(3.442 \%)$ \\
market hours & 0.153 & $0.163(6.174 \%)$ \\
home hours & 0.150 & $0.151(0.433 \%)$ \\
leisure & 0.697 & $0.687(-1.451 \%)$ \\
Welfare changes & & $19.064 \%$ \\
\hline
\end{tabular}


Table 5. Calibration to Match Data Moments - without Home Production

\begin{tabular}{cll} 
Parameters $(6)$ & Without Home Production \\
\hline$\beta$ & discount factor & 0.953 \\
$\tau$ & Social Security tax & 0.102 \\
$\omega_{1}$ & weight on durable & 0.734 \\
$\omega_{3}$ & weight on market goods & 0.583 \\
$\zeta_{4}$ & sub. betw. consumption and leisure & 1.419 \\
$\omega_{4}$ & weight on consumption & 0.089 \\
\hline
\end{tabular}

Table 6. Aggregate Effects of Eliminating Social Security Benefits

\begin{tabular}{|c|c|c|c|}
\hline \multirow[b]{2}{*}{ Variable } & \multicolumn{3}{|c|}{ relative changes after the reform } \\
\hline & benchmark & no home prod. & one-good \\
\hline interest rate $(r)$ & $-12.640 \%$ & $-11.923 \%$ & $-13.276 \%$ \\
\hline wage $(w)$ & $1.470 \%$ & $1.384 \%$ & $3.400 \%$ \\
\hline capital output ratio $(K / Y)$ & $4.729 \%$ & $4.449 \%$ & $7.340 \%$ \\
\hline aggregate capital & $9.278 \%$ & $9.984 \%$ & $15.631 \%$ \\
\hline aggregate labor & $2.832 \%$ & $3.861 \%$ & $4.182 \%$ \\
\hline total housing & $17.114 \%$ & $20.544 \%$ & \\
\hline home input & $0.560 \%$ & $4.453 \%$ & \\
\hline market consumption & $3.442 \%$ & $3.133 \%$ & $5.891 \%$ \\
\hline market hours & $6.174 \%$ & $7.232 \%$ & $7.925 \%$ \\
\hline home hours & $0.433 \%$ & & \\
\hline leisure & $-1.451 \%$ & $-1.303 \%$ & $-1.437 \%$ \\
\hline welfare & $19.064 \%$ & $16.060 \%$ & $10.400 \%$ \\
\hline
\end{tabular}

Table 7. Calibration to Match Data Moments - One-good Economy

\begin{tabular}{cll} 
Parameters $(4)$ & One-good Economy \\
\hline$\beta$ & discount factor & 0.953 \\
$\tau$ & Social Security tax & 0.102 \\
$\zeta_{4}$ & sub. betw. consumption and leisure & 1.421 \\
$\omega_{4}$ & weight on consumption & 0.075 \\
\hline
\end{tabular}




\section{References}

[1] Abbott, Michael, Orley Ashenfelter, 1976. "Labor Supply, Commodity Demand, and the Allocation of Time," Review of Economic Studies 43, 395-412.

[2] Aguiar, Mark, and Erik Hurst. 2009. "Deconstructing Lifecycle Expenditure," NBER Working Paper No. 13893.

[3] Attanasio, Orazio, James Banks, Costas Meghir and Guglielmo Weber, 1999. "Humps and Bumps in Lifetime Consumption," Journal of Business and Economic Statistics 17, 22-35.

[4] Barnett, William. 1979. "The Joint Allocation of Leisure and Goods Expenditure," Econometrica 47, 539-563.

[5] Baxter, Marianne, and Dana Rotz, 2009. "Detecting Household Production," University of Boston, manuscript.

[6] Baxter, Marianne and Urban J. Jermann. 1997. "The International Diversification Puzzle Is Worse Than You Think." American Economic Review, 170-180

[7] Benhabib, Jess, Richard Rogerson, and Randall Wright. 1991. "Homework in Macroeconomics: Household Production and Aggregate Fluctuations." Journal of Political Economy, 99, 1166-1187.

[8] Chang, Yongsung, and Andreas Hornstein. 2008. "Home Production and Macroeconomics," New Palgrave Dictionary of Economics 2nd edition, New York, McMillan.

[9] Chen, Kaiji. 2010. "A Life-cycle Analysis of Social Security with Housing," Review of Economic Dynamics, 13(3), 597-615.

[10] Dotsey, Michael, Wenli Li, and Fang Yang. 2010. "Consumption and Time Use over the Life Cycle," Federal Reserve Bank of Philadelphia Working Paper 10-37.

[11] Fuster, Luisa. 1999. "Is Altruism Important for Understanding the Long-run Effects of Social Security?" Review of Economic Dynamics 2(3), 616-637.

[12] Fuster, Luisa, Ayse Imrohoroglu and Selahattin Imrohoroglu. 2003. "A Welfare Analysis of Social Security in a Dynastic Framework," International Economic Review 44(4), 1247-1274. 
[13] Fuster, Luisa, Ayse Imrohoroglu and Selahattin Imrohoroglu. 2007. "Elimination of Social Security in a Dynastic Framework," Review of Economic Studies 74(1), 113-145.

[14] French, Eric. 2005. "The Effects of Health, Wealth and Wages on Labor Supply and Retirement Behavior," Review of Economic Studies, 72(2), 395-427.

[15] Gervais, Martin. 2002. "Housing Taxation and Capital Accumulation," Journal of Monetary Economics, 49, 1461-1489.

[16] Gomme, Paulm, Finn Kydland and Peter Rupert. 2001. "Home Production Meets Time to Build." Journal of Political Economy 109(5), 1115-1131.

[17] Gourinchas, Pierre-Olivier, and Jonathan A. Parker, 2002. "Consumption over the Life Cycle," Econometrica, 70, 47-89.

[18] Greenwood, Jeremy, and Zvi Hercowitz, 1991. "The Allocation of Capital and Time over the Business Cycle," Journal of Political Economy, 99 (6), 1188-1214.

[19] Greenwood, Jeremy, Richard Rogerson, and Randall Wright. 1995. "Household Production in Real Business Cycle Theory," in T. Cooley, Frontiers of Business Cycle Research. Princeton, NJ: Princeton University Press. 157-74.

[20] Huggett, Mark, 1996. "Wealth Distribution in Life-Cycle Economies," Journal of Monetary Economics, 38(3), 469-494.

[21] Huggett, Mark, and Gustavo Ventura. 1999. "On the Distributional Effects of Social Security Reform." Review of Economic Dynamics 2, 498-531.

[22] Imrohoroglu, Selahattin, and Kitao, Sagiri. 2009. "Labor Supply Elasticity and Social Security Reform.” Journal of Public Economics, 93, 867-878.

[23] Imrohoroglu, Selahattin, and Kitao, Sagiri. 2012. "Social Security, Benefit Claiming and Labor Force Participation and Long-Run Sustainability." American Economic Journal: Macroeconomics, forthcoming.

[24] McGrattan, Ellen, Richard Rogerson, and Randall Wright, 1997. "An Equilibrium Model of the Business Cycle with Household Production and Fiscal Policy," International Economic Review, 38(2), 267-290.

[25] Nishiyama, Shinichi, and Kent Smetters. 2007. "Does Social Security Privatization Produce Efficiency Gains?" Quarterly Journal of Economics, 122(4), 1677-1719. 
[26] Reid, Margaret G., 1934. Economics of Household Production, New York: John Wiley \& Sons, Inc.

[27] Rogerson, Richard. 2009. "Market Work, Home Work, and Taxes: A Cross-Country Analysis," Review of International Economics, 17(3), 588-601.

[28] Rogerson, Richard, and Johanna Wallenius. 2009. "Retirement in a Life Cycle Model of Labor Supply with Home Production," Working Paper. Arizona State University.

[29] Rupert, Peter, Richard Rogerson, and Randall Wright, 2000. "Homework in Labor Economics: Household Production and Intertemporal Substitution, "Journal of Monetary Economics, 46, 557-579.

[30] Sato, K., 1967. "A Two-Level Constant-Elasticity-of-Substitution Production Function," Review of Economic Studies, 34(2), 201-218. 